\title{
Correction to: Whole Exome Sequencing Identifies Two Novel Mutations in the Reticulon 4-Interacting Protein 1 Gene in a Chinese Family with Autosomal Recessive Optic Neuropathies
}

\author{
Xiao-Huan Zou ${ }^{1} \cdot$ Xin-Xin Guo $^{1} \cdot$ Hui-Zhen $\mathrm{Su}^{1} \cdot$ Chong Wang $^{1} \cdot$ En-Lin Dong ${ }^{1} \cdot$ Ning Wang $^{1,2} \cdot$ Wan-Jin Chen ${ }^{1,2}$. \\ Qi-Jie Zhang ${ }^{1,2}$
}

Published online: 11 January 2020

(C) Springer Science+Business Media, LLC, part of Springer Nature 2019

Correction to: J Mol Neurosci (2019) 68:640-646

https://doi.org/10.1007/s12031-019-01319-7

The original version of this article unfortunately contained mistakes in the affiliation section. The first and second affiliations were inadvertently interchanged. The organization name "Fujian Medical University" should also be corrected to "First Affiliated Hospital of Fujian Medical University".

The correct presentation of the affiliations is shown below.

Publisher's Note Springer Nature remains neutral with regard to jurisdictional claims in published maps and institutional affiliations.

The online version of the original article can be found at https://doi.org/ 10.1007/s12031-019-01319-7

\footnotetext{
Wan-Jin Chen

wanjinchen75@fjmu.edu.cn

Qi-Jie Zhang

403278692@qq.com

1 Department of Neurology and Institute of Neurology, First Affiliated Hospital of Fujian Medical University, 20 Chazhong Road, Fuzhou 350005, China

2 Fujian Key Laboratory of Molecular Neurology, Fuzhou, China
} 